\title{
Carmen Trillo San José, La VeGa de Granada A PARTIR DE DOCUMENTACIÓN ÁRABE ROMANCEADA INÉDITA (1457-1494). ESTUDIO, EDICIÓN E ÍNDICES. Suomalainen Tiedeakatemia AnNales Academiae Scientiarum FenNicae. Humaniora 384 HELSINKI, 2020, 154 PÁGS. ISBN: 978-951-41-1151-8.
}

\author{
María Martínez MartíneZ \\ Universidad de Murcia
}

Carmen Trillo, catedrática de Historia Medieval de la Universidad de Granada, publica en la prestigiosa Academia Scientarum Fennica, la monografía La Vega de Granada a partir de documentación árabe romanceada inédita (1457-1494). La acotación temporal de esta obra es sustancial para conocer el proceso de transición previo a la conquista del reino nazarí y sus inmediatas consecuencias. La autora, conocida especialista ligada al ámbito investigador de la Alpujarra granadina (La Alpujarra, antes y después de la conquista castellana, 1998, $2^{\mathrm{a}}$ ed.), es un referente en la historia andalusí granadina. La combinación de registros documentales y arqueológicos han permitido a Trillo explotar al máximo las fuentes para interpretar transversalmente la sociedad, sus grupos y formas de asentamiento, el poblamiento, los espacios interrelacionados urbano, periurbano y rural y el condicionamiento del agua en las estructuras socioeconómicas y espaciales, como demuestra en algunas de sus obras en estas dos décadas de siglo: Una sociedad rural en el Mediterráneo occidental (2003), Mujeres, familias y linaje en la Edad Media (2004), Agua, tierra y hombres en al-Andalus (2004), El agua en al-Andalus (2009) y la coordinación del estudio colectivo de las almunias o fincas aristocráticas en el Occidente islámico (2018).

En la monografía que se reseña ahora, la profesora Trillo exhuma una provechosa documentación árabe romanceada de la segunda mitad del siglo XV, valiosa para medievalistas en cualquier especialidad (historia andalusí y castellana, arqueología, filología, geografía, historia institucional, diplomática, paleografía, ecohistoria, etc.), circunscrita a la comarca de la Vega de Granada, un espacio periurbano de transición entre la ciudad y el mundo rural. En sí mismo este libro tiene el interés de proporcionar un importante volumen de documentos árabes romanceados inéditos de finales del siglo XV sobre la 
Vega de Granada. Y dada la escasez de documentos árabes y árabes romanceados en al-Andalus, esta aportación es fundamental para la historia del reino nazarí de Granada (1238-1492) en la segunda mitad del siglo XV, así como para explicar los cambios tras su incorporación a la corona castellana. A ello se añade la capacidad interpretativa de la autora para contextualizar y extraer de dichas fuentes escritas un acopio de precisiones aplicadas con metodología y rigor a varios aspectos que cohesionan y completan la monografía. Desde el documento escrito Trillo elabora una arqueología espacial o del paisaje de la vega granadina que, sin caer en el localismo rancio, será sin duda muy aprovechable para futuras investigaciones de arqueólogos-historiadores medievalistas o la inversa.

Acotado el tiempo y el espacio donde se encierra el centenar y medio de páginas, la obra se divide en dos partes claramente diferenciadas. La primera es un estudio del marco geográfico e histórico de la Vega de Granada al final de la Edad Media, el tipo de asentamientos y la propiedad agrícola. La segunda es la relación de documentos para el estudio del reino de Granada y la edición de 22 documentos (1457-1551), en los que están insertos 65 escrituras en árabe romanceado (1457-1494), que fueron traducidas por el escribano converso y romanceador Ambrosio Xarafí en 1509. Se trata de una pieza de 1780 en donde se recogen las copias de 65 documentos árabes romanceados (1457-1494) sobre la Vega de Granada, que fueron traducidos a principios del siglo XVI por el citado escribano granadino Ambrosio Xarafí. Dichas escrituras fueron utilizadas en un pleito de 1780 entre el Marqués de Santa Cruz y conde de Monte Santo, dueño de los cortijos de Asquerosa y Daragedid, contra el Almirante de Aragón y Marqués de los Trujillos, poseedores del cortijo de Daimuz el alto, y el Conde de Sástago, poseedor del de Daragoleja, por el despojo de la tercera parte del agua de la acequia que se toma de los ríos Velillos y Cubillas, propiedad del marqués. El documento es el sujeto sobre el que se sustenta la publicación de Trillo para configurar una sólida percepción de la estructura del poblamiento de la vega granadina. Un pleito que clarifica los espacios del poder del antiguo patrimonio real nazarí y de los nuevos linajes sobre el territorio. A partir de esta documentación la autora reflexiona acerca del espacio geográfico y social de la Vega de Granada, considerado hacia finales de la Edad Media el hinterland de Madina Garnata. Se centra sobre todo en la Vega noroccidental, un territorio periurbano que en época nazarí se caracteriza por su proximidad a la frontera, por recibir frecuentes incursiones castellanas y por la presencia de importantes propiedades del patrimonio real, generalmente fortificadas con torres. Todos estos hechos están relacionados, y la autora los pone además en conexión con las diversas formas en que el emir nazarí podía convertirse en propietario: confiscación, herencia, venta y vivificación. De lo que se concluye que los reyes nazaríes fueron apropiándose de espacios en la zona de frontera y fortificándolos para defensa de sus propiedades y del territorio en general. Sobre dicho espacio fronterizo castellano-nazarí, Trillo traza un panorama general del poblamiento y las explotaciones agrícolas en dicho periodo, mostrando y diferenciando los tipos de alquerías existentes, la existencia de almunias reales y aristocráticas y otras tierras del patrimonio regio. Ha de destacarse la importancia de este tipo de documentación árabe 
romanceada para el conocimiento del reino de Granada en época nazarí y en el tránsito al dominio castellano, un proceso fundamental para ver las posibles continuidades y las rupturas inmediatas.

Trillo construye un primer estudio de lo extraído del documento que edita, teniendo en cuenta diversos aspectos interrelacionados de economía y sociedad y poder. En ese sentido hace observaciones sobre las propiedades que compró don Álvaro de Bazán —un linaje procedente de Batzán, Navarra - en la Vega de Granada a los nazaríes, así como sobre otros documentos anteriores que muestran las ventas efectuadas de propietarios musulmanes. De dicha interpretación se deriva el tipo de sociedad que reflejan esos textos mediante la forma en que se nombran a los individuos, los lazos familiares que se aprecian entre ellos, la manera en que están presentes las mujeres que intervienen en las transacciones realizadas, los cargos de la administración que tenían los compradores y vendedores y algunas valoraciones de otros grupos sociales.

Así pues, la autora define bien el área de estudio, recorre el tiempo histórico acotado en la Vega de Granada y el contexto geohistórico de la documentación editada, poniendo de relieve los diferentes tipos de asentamientos y propiedades agrícolas de la Vega nazarí. Aprovechando la rica información del texto editado, junto a las descripciones realizadas por Ibn al-Jatib, las crónicas y la documentación castellana, la autora esboza el complejo paisaje de la Vega: tipos de alquerías (alquerías-village, alquerías-cortijo, alquerías-finca, torres, tierras de patrimonio real, propiedades de las élites urbanas, tierras de los campesinos, terrenos comunales y otros apropiables por vivificación, bienes habices, propiedades y propietarios. Esta diversidad de asentamientos en la ocupación y explotación del espacio es una muestra de la influencia urbana en el hinterland de la ciudad de Granada.

Esta obra permite la comprensión del paisaje bajomedieval de la Vega de Granada y el funcionamiento del patrimonio real, utilizado por la corona nazarí como un recurso para ser autosuficiente respecto al tesoro público. Con esta base material el rey conseguía sustentarse él y su familia, pagar eventualmente a funcionarios y partidarios, financiar guerras, etc. En suma, la obtención de patrimonio era un medio para mantener el poder. Es probable que este patrimonio real, que se ubica en buena medida en esta zona de la Vega occidental, fueran las calificadas como alquerías-finca. $Y$ en el mismo sentido, la autora trata de diferenciar estas alquerías particulares de lo que serían las almunias, pero sin llegar a una conclusión definitiva. Resulta valioso el minucioso y combinado análisis de los datos extraídos de la documentación realizado por Trillo con los que identifica a los propietarios urbanos en la Vega, sobre todo a las élites que a lo largo del siglo XV van a ir adquiriendo bienes que, en su mayor parte, pertenecían al patrimonio real, principalmente en Daragedid (hoy Casas Nuevas en Pinos Puente), y en Asquerosa. La parte final del libro está orientada a analizar el texto que se edita. La importancia de estos documentos es fundamental sobre todo por la exigüidad de documentación árabe y árabe romanceada de archivo. Pese a ser una copia tardía, de 1780, su autenticidad está refrendada por la aparición de topónimos y antropónimos en otros textos árabes 
medievales. En resumen, se trata de un libro que se sitúa en el centro del debate historiográfico sobre qué tipo de sociedad es al-Andalus. Samir Amín popularizó la categorización de al-Andalus como sociedad tributaria, dividida en dos esferas diferentes: el campesinado y el Estado. Manzano propuso una revisión de este concepto analizando precisamente la influencia del Estado y sus funcionarios en las zonas rurales. Esta obra nos va a permitir conocer cómo funcionaba el área periurbana de una gran ciudad como Granada y precisar cómo pudo ser esta influencia estatal y urbana en la segunda mitad del siglo XV. En ella vemos que, junto a las alquerías de las comunidades rurales, se encuentran otras alquerías, con frecuencia fortificadas, que son propiedad particular del rey, su familia y algunos cargos del gobierno. Asimismo constatamos que, una vez más durante el conflictivo reinado de Sa'd (1454-1455, 1455-1462 y 1463-1464), se producen enajenaciones del patrimonio real, seguramente para hacer frente a las divisiones internas. Aquellas continuarán, no obstante, hasta finales del siglo XV, siendo los beneficiarios alcaides, ricos mercaderes, probablemente de Granada, y judíos, lo que refleja una sociedad jerarquizada y urbana, pese a tratarse de un ámbito rural. Finalmente, el comprador de estas propiedades va a ser don Álvaro de Bazán, marqués de los Trujillos. Se concluye que el hinterland de Granada presentaba unas características diferentes desde el punto de vista de los asentamientos y la propiedad de la tierra respecto a otras zonas rurales. Sin duda ello se debía a la influencia de la capital nazarí en su espacio inmediato, y con ella la de la presión del Estado, el rey y las élites.

El estudio, intercalado de pertinentes ilustraciones, adjunta la edición del manuscrito y aclaratorios índices onomástico y toponímico. Y termino con las propias palabras de la autora: “...dada la escasez de documentación árabe coetánea, lo que convierte a estos textos en piezas clave para la interpretación de la historia social, económica, institucional, etc. de dicha época". 